\title{
Toposym 4-B
}

\section{Ivan Ivanšić}

\section{Embedding compacta up to shape}

In: Josef Novák (ed.): General topology and its relations to modern analysis and algebra IV, Proceedings of the fourth Prague topological symposium, 1976, Part B: Contributed Papers. Society of Czechoslovak Mathematicians and Physicist, Praha, 1977. pp. 178.

Persistent URL: http://dml.cz/dmlcz/700641

\section{Terms of use:}

(C) Society of Czechoslovak Mathematicians and Physicist, 1977

Institute of Mathematics of the Academy of Sciences of the Czech Republic provides access to digitized documents strictly for personal use. Each copy of any part of this document must contain these Terms of use.

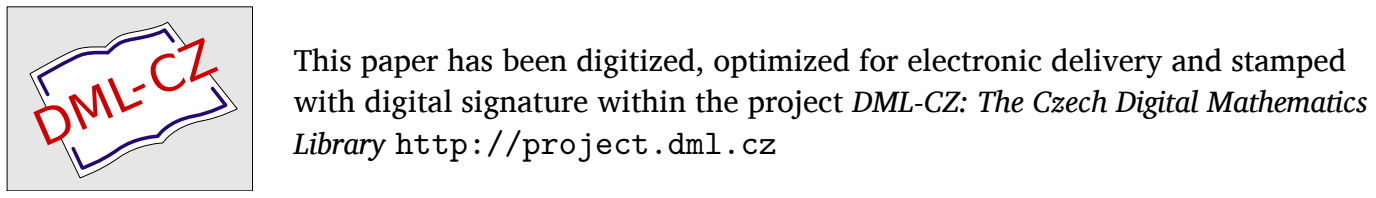




\section{EMBEDDING COMPACTA UP TO SHAPE}

\section{IVANSIC}

\section{Zagreb}

This is the abstract of [1] in which we prove some results on ombedding of metric compacta up to shape into Euclidean spaces. Namely, we find some sufficient conditions when a pointed compactum $X$ of the shape dimension $S a(X, x)$ can be embedded up to shape into $E^{d}$ for $q<2 \operatorname{Sa}(X, X)+1$, where embedding of $X$ into $Y$ up to shape moans that there is a subspace $X^{\circ} C Y$ of the same shape as $X$. The main result is

Theorem 1. Iet $M$ be a PL manifold without boundary of dimension $q$ and let $\left\{\left(P_{k}, x_{k}\right), p_{k, k+1}\right\}$ be a tower of polyhedra such that

(1) all $P_{k}$ are of dimension $\leqq n, q-n \geqq 3$;

(ii) all bonding maps are $(2 n-q+1)$-connected, and

(1ii) there is a $(2 n-q+1)$-connected map $p_{O I}: P_{I} \rightarrow \mathbf{M}$. Then there is a pointed compactun I C $M$ such that $\operatorname{Sh}(Y, y)=$ $=\mathrm{Sh} \operatorname{lin}_{\leftarrow}\left\{\left(\mathrm{P}_{\mathbf{k}}, \mathrm{x}_{\mathbf{k}}\right), \mathrm{P}_{\mathbf{k}, \mathbf{k}+1}\right\}$.

Using Theorem 1 and some other lemmes and stability theorems of D. A. Edwards and R. Geoghegen one gets

Theorem 2. If $X$ is a pointed compactum, $S a(X, x)=n$, which is r-ehape connected, $n-x \geqslant 2$, thes $(x, x)$ can be embedded up to shape into $\mathrm{E}^{2 \mathrm{n}-\mathrm{r}+1}$.

Theorem 3. Iet $X$ be pointed compectum which is pointed shape dominated by a polyhedron and let $\operatorname{Sa}(x, x)=n \geqq 3$. If $(x, x)$ has trivial shape groups for $1 \leqq 1 \leqq r, n-r \geqq 3$, then $(x, x)$ can be embedded up to shape into $\mathrm{r}^{2 n-r}$.

\section{Reference}

[1] I. Ivansic: Bmbedding compacta up to shape. Submitted to Bull. lead. Polon. Se1. Ser. Se1. Math. Astronom. Phys. 